http://dx.doi.org/10.4314/ajtcam.v11i5.17

\title{
INHIBITION EFFECTS OF SCORPION VENOM EXTRACTS (BUTHUS MATENSII KARSCH) ON THE GROWTH OF HUMAN BREAST CANCER MCF-7 CELLS
}

\author{
Weiling $\mathrm{Li}^{1}$, Ye $\mathrm{Li}^{1}$, Yuwan Zhao ${ }^{1}$, Jieli Yuan ${ }^{2}$, Weifeng Mao ${ }^{1}$ \\ ${ }^{1}$ Department of Biotechnology, Dalian Medical University, Dalian, P.R.China 116044, ${ }^{2}$ Department of Microecology, \\ Dalian Medical University, Dalian, P.R.China 116044 \\ Author for correspondence: \\ Jieli Yuan, Department of Microecology, Dalian Medical University, Dalian, 116044, China. \\ Weifeng Mao, Department of Biotechnology, Dalian Medical University, Dalian, 116044, China. \\ Email:maoweife@gmail.com
}

\begin{abstract}
Background: To observe the inhibition effects of the Buthus matensii Karsch (BmK) scorpion venom extracts on the growth of human breast cancer MCF-7 cells, and to explore its mechanisms.

Methods: Two common tumor cells (SMMC7721, MCF-7) were examined for the one which wasmore sensitivity to scorpion venom by MTT method. Cell cycle was determined by flow cytometry. Immunocytochemistry was applied to detect apoptosis-related protein Caspase-3 and Bcl-2 levels, while the expression of cell cycle-related protein Cyclin D1 was shown by Western blotting.

Results: Our data indicated that MCF-7 was the more sensitive cell line to scorpion venom. The extracts of scorpion venom could inhibit the growth and proliferation of MCF-7 cells. Furthermore, the extract of scorpion venom induced apoptosis through Caspase-3 up-regulation while Bcl-2 down-regulation in MCF-7 cells. In addition, the extracts of scorpion venom blocked the cells from $\mathrm{G}_{0} / \mathrm{G}_{1}$ phase to $\mathrm{S}$ phase and decreased cell cycle-related protein Cyclin D1 level after drug intervention compared with the negative control group.
\end{abstract}

Conclusions: These results showed that the BmK scorpion venom extracts could inhibit the growth of MCF-7 cells by inducing apoptosis and blocking cell cycle in $\mathrm{G}_{0} / \mathrm{G}_{1}$ phase. The BmK scorpion venom extracts will be very valuable for the treatment of breast cancer.

Key words: Apoptosis, Buthus matensii Karsch, cell cycle, MCF-7, scorpion venom

\begin{abstract}
Abbreviations: SVE: Scorpion venom extracts ; FBS: Fetal bovine serum; MTT: 3-(4, 5-Dimethylthiazol-2-yl)-2, 5-diphenyltetrazolium bromide; BmK ; Buthus matensii Karsch; PBS: Phosphate buffered saline; PI: Propidium iodide; FCM: Flow cytometry; SDS-PAGE: Sodium dodecyl sulfate polyacrylamide gel electrophoresis; DAB: Diaminobenzidine; B-NHL: B-cell non-Hodgkin's tumors; DED: Death effector domain ; PTP: Permeability transition pores ; CKIs: Cyclin-dependent kinases inhabitors; pRB: Retinoblastoma tumor suppressor protein ; CDK: Cyclin-dependent kinases
\end{abstract}

\section{Introduction}

Neoplastic diseases have becoming more and more important in the medical field for half a century. They have been frequently-occurring and common diseases that are the $1^{\text {st }}$ reason for human death and are seriously threatening human health. Therefore, it has been hot topics for researchers in the scientific community to explore high efficient and low toxic anti-cancer drugs and treatment methods. Besides the traditional surgery, chemotherapy and radiotherapy, more and more attention has also been paid to biological therapies and Integrative Medicine.

Scorpion venom is a biological toxin, mainly consisting of non-protein and protein components (Zhou X, 1984). Non-protein components include lipids, organic acids and a small amount of free amino acids. The main active ingredients are its protein components, and majority of them are polypeptides consisting of 20-80 amino acids. The active proteins are divided into toxic proteins and enzymatic proteins by their different functions (Wang Y, 2000). Scorpion venom has attracted much attention because of its extensive physiological effects. They are known to have 


\section{http://dx.doi.org/10.4314/ajtcam.v11i5.17}

anti-epileptic, anti-cancer, analgesic, and fibrinolytic activity. It has been reported that scorpion venom (Buthus matensii Karsch) can significantly inhibit the proliferation of human esophageal cancer cell line Eca109 and human colon cancer cell line HR8348, reduce mitotic index and clone formation efficiency, and significantly extend the survival time of mice having Ehrlich ascites carcinoma (Wu, 1993).

In recent years, scorpion venom has been paid more and more attention as an anti-cancer, anti-epileptic drug. Although there were many reports on the research of anti-cancer effects of scorpion venom, its anti-cancer mechanism remains unclear. Since the effective doses of scorpion venom as an anti-cancer drug vary significantly due to different sensitivity and affinity of different cell lines, this paper started with two types of cancer (liver cancer and breast cancer) with higher clinical incidences to compare their sensitivity and affinity to Buthus matensii Karsch (BmK) scorpion venom. The tumor cells which were most sensitive to BmK scorpion venom were selected as the research subject to investigate its anti-cancer mechanisms. This paper further explored the anti-cancer mechanisms of BmK scorpion venom from the induction of apoptosis with the more sensitive cell line human breast cancer cells (MCF-7). These results will provide an experimental basis for further purification of the anti-cancer composition in BmK scorpion venom and development and clinical application of this anti-cancer drug.

\section{Materials and Methods \\ Cell culture (Fracchiolla et al., 1997)}

Two cell lines used in this project were human hepatoma cell line (SMMC 7721), human breast cancer cell line (MCF-7). All cell lines were stored in our laboratory and subcultured RPMI 1640 medium (GIBCO, USA) supplemented with 10\% fetus bovine serum (FBS) (GIBCO, USA) at $37 \square$ with $5 \% \mathrm{CO}_{2}$. Cells were treated with serial concentrations of the BmK scorpion venom extracts (SVE) and the untreated cells were used as negative controls.

\section{Cell survival experiments (Btieler H, 2010)}

Cell survival was examined with tetrazolium salt (MTT) assay (Amerco, USA). Two types of tumor cells (MCF-7 and SMMC7721) were seeded at $3 \times 10^{3}$ cells /well in 96-well plates. When the cells were completely adhere to the wells after $16 \mathrm{~h}, 20 \mu \mathrm{l}$ different concentration of experimental BmK scorpion venom protein was added to each well. Six wells were used for each concentration. After being incubated for $24 \mathrm{~h}$, MTT $(5 \mathrm{mg} / \mathrm{mL})$ was added to each well and then after $4 \mathrm{~h}$ incubation, each well was detected.

\section{Detection of apoptosis proteins by immunocytochemistry (Hirsch T et al., 1998)}

Climbing cell slices were treated with the BmK scorpion venom $(600 \mu \mathrm{g} / \mathrm{mL})$ for $24 \mathrm{~h}$ and fixed in $4 \%$ paraformaldehyde for $15 \mathrm{~min}$ at room temperature. After being washed twice with PBS for 3 min each, the cells were incubated in $3 \% \mathrm{H}_{2} \mathrm{O}_{2}$ deionized water for 15 min, preincubated with $2 \%$ blocking serum for $15 \mathrm{~min}$ at room temperature. After incubation with the primary antibody for $1 \mathrm{~h}$ at room temperature, the slides were washed twice with PBS for 3 min each again. Then the cells were added with the secondary antibody and incubated at $37 \square$ for 20 min. After washing twice with PBS for $3 \mathrm{~min}$ each, the cells were visualized with dimethylbenzene solution. The following antibodies were used in immunocytochemistry staining: caspase-3 (1:1000, Santa Cruz, USA) and Bcl-2 (1:1000, Santa Cruz, USA).

\section{Changes of cell cycle measured by flow cytometry (Jamil Z et al., 2001)}

Changes of the cell cycle were examined with PI labeling by flow cytometry (FCM). The cells were inoculated to a 24-well culture plate $\left(1 \times 10^{5}\right.$ cells $/$ well) and cultured for $16 \mathrm{~h}$, they were added with $600 \mu \mathrm{g} / \mathrm{mL}$ of BmK scorpion venom and cultured for 24 hours before being harvested. The cells were washed twice with PBS, and added with $50 \mu 1 \mathrm{RNase}(10 \mu \mathrm{g} / \mathrm{mL})$ and $200 \mu \mathrm{l}$ PI (5 $\mu \mathrm{g} / \mathrm{mL})$ (Sigma, USA). After being incubated for $30 \mathrm{~min}$ at $4 \square$ in dark, the cells were detected by flow cytometry. 
http://dx.doi.org/10.4314/ajtcam.v11i5.17

Changes of the expression of cell cycle protein CyclinD1 examined by Western blotting (Arber N et al., 1997)

MCF-7 cells were treated with $600 \mu \mathrm{g} / \mathrm{mL}$ of BmK scorpion venom for $24 \mathrm{~h}$. Protein samples were subjected to SDS-PAGE and transferred from gel to a nitrocellulose membrane with a semi-dry transfer apparatus. Western blots were probed with specific antibodies. The protein bands were detected by enhanced chemiluminescence.

\section{Results}

Effects of scorpion venom on survival rate of human breast cancer cells (MCF-7) and human hepatoma cells (SMMC7721)

MTT assay was used to observe the effects of different protein concentration $(100 \mu \mathrm{g} / \mathrm{mL}, 200 \mu \mathrm{g} / \mathrm{mL}, 400 \mu \mathrm{g} / \mathrm{mL}, 600 \mu \mathrm{g} / \mathrm{mL}, 800 \mu \mathrm{g} / \mathrm{mL})$ of experimental BmK scorpion venom on the survival rate of human breast cancer cells (MCF-7) and human hepatoma cells (SMMC7721) at 0h, 4h, $8 \mathrm{~h}, 12 \mathrm{~h}, 16 \mathrm{~h}, 24 \mathrm{~h}$. The results showed that: (1) Along with the increasing concentration of the protein and the extension of time, BmK scorpion venom significantly inhibited the growth of both MCF-7 and SMMC7721 cells. (2) For the sensitivity of these two cell lines to BmK scorpion venom, MCF-7 cells were more sensitive to BmK scorpion venom compared to SMMC7721 cells with the same time point and the same concentration of the drug. The results were shown in Fig. 1 and Fig. 2.

\section{Inhibition Rate}

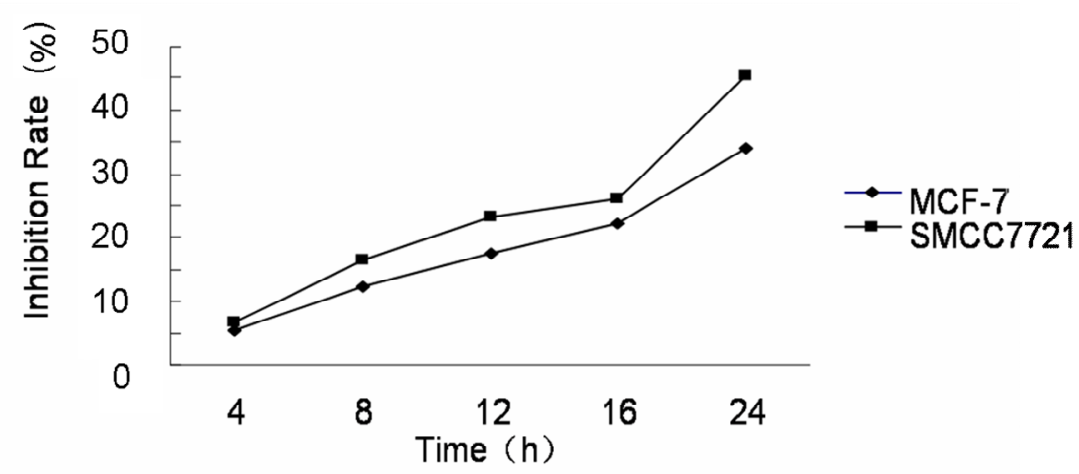

Figure 1: Effects of scorpion venom on survival rate of human breast cancer cells (MCF-7) and human hepatoma cells (SMMC7721) at various times. Effect of BmK scorpion venom extracts on the growth of human breast cancer cells (MCF-7) and human hepatoma cells (SMMC7721) at various times. Cells were treated with BmK scorpion venom extracts $(600 \mu \mathrm{g} / \mathrm{mL})$ for different time (4h, $8 \mathrm{~h}, 12 \mathrm{~h}, 16 \mathrm{~h}, 24 \mathrm{~h})$. The inhibiting rate of the cell growth was determined by MTT assay and expressed using the following equation: inhibiting rate $(\%)=(1-\mathrm{Abs}$ test $/ \mathrm{Abs}$ cont). The data were the average from two independent assays

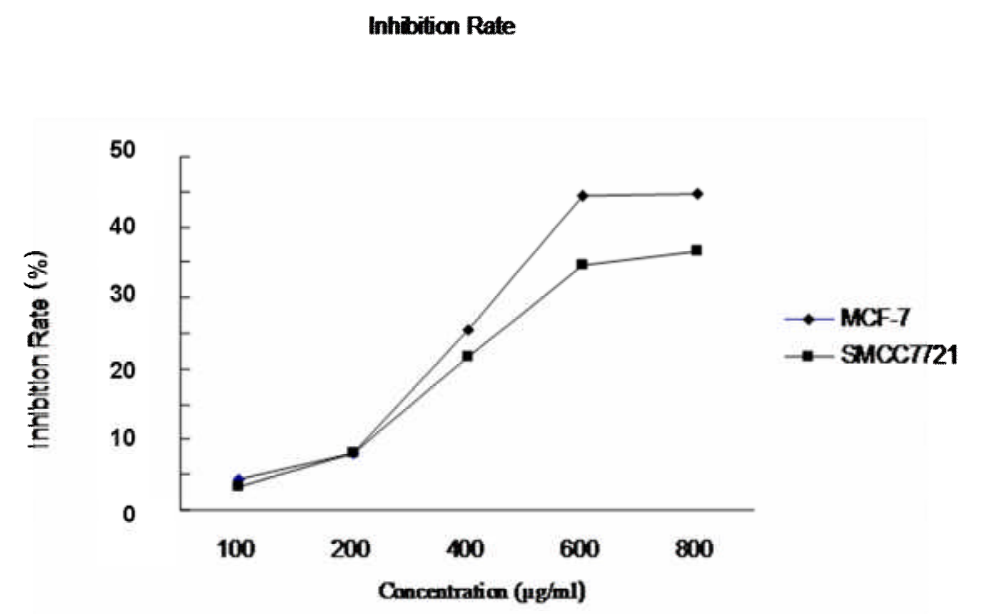

Figure 2: Effects of different concentrations of scorpion venom on survival rate of human breast cancer cells (MCF-7) and human hepatoma cells (SMMC7721). Effect of different concentrations of BmK scorpion venom extracts on the growth of human breast cancer cells 


\section{http://dx.doi.org/10.4314/ajtcam.v11i5.17}

(MCF-7) and human hepatoma cells (SMMC7721). Cells were treated with scorpion venom extracts $(100 \mu \mathrm{g} / \mathrm{mL}, 200 \mu \mathrm{g} / \mathrm{mL}, 400 \mu \mathrm{g} / \mathrm{mL}$, $600 \mu \mathrm{g} / \mathrm{mL}, 800 \mu \mathrm{g} / \mathrm{mL}$ ) for $24 \mathrm{~h}$. The inhibiting rate of the cell growth was determined by MTT assay and expressed using the following equation: inhibiting rate $(\%)=\left(1-\mathrm{Abs}_{\text {test }} / \mathrm{Abs}_{\text {cont }}\right)$. The data were the average from two independent assays.

\section{Effects of experimental BmK scorpion venom on the expression of apoptotic proteins}

To further investigate whether BmK scorpion venom induced apoptosis of breast cancer cells, we detected apoptotic proteins. Immunocytochemical assay results showed that the expression of pro-apoptotic protein Caspase-3 increased while that of apoptosis suppression protein Bcl-2 decreased after the MCF-7 cells treated with $600 \mu \mathrm{g} / \mathrm{mL}$ BmK scorpion venom for $24 \mathrm{~h}$ (the control group was treated without scorpion venom) (Fig.3).

A

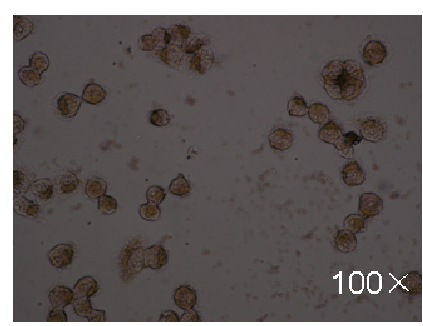

C

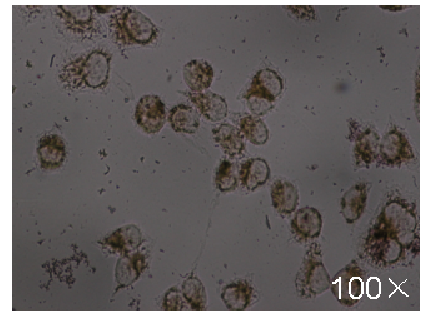

B

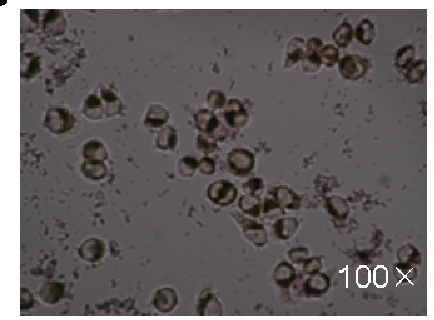

D

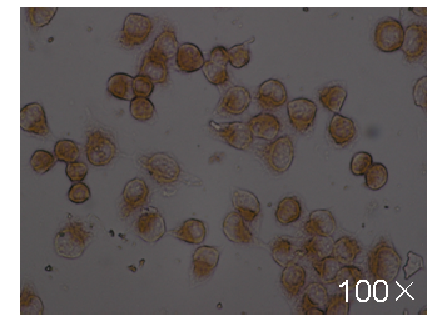

Figure 3: Effects of experimental BmK scorpion venom on the expression of apoptotic proteins. Scorpion venom extract induces activation of intrinsic apoptotic pathway. A and B, Representative immunohistochemistry photograph under microscope $(100 \times)$ of control and $600 \mu \mathrm{g} / \mathrm{mL}$ BmK scorpion venom extracts treated MCF-7 cells stained for caspase-3. C and D, Representative Immunohistochemistry photograph under microscope $(100 \times)$ of controls and $600 \mu \mathrm{g} / \mathrm{mL} \mathrm{BmK}$ scorpion venom extracts treated MCF-7 cells stained for Bcl-2.

\section{Effects of experimental BmK scorpion venom on the cell cycle of MCF-7 cells}

Changes of the cell cycle were examined with PI labeling by FCM. The results showed that after the MCF-7 cells were treated with 600 $\mu \mathrm{g} / \mathrm{mL}$ BmK scorpion venom for $24 \mathrm{~h}$, the cell number in $\mathrm{G}_{0} / \mathrm{G}_{1}$ phase significantly increased compared with the control group without adding the drug $(\mathrm{P}<0.05)$; and that in $\mathrm{G}_{2} / \mathrm{M}$ phases didn't change significantly while that in $\mathrm{S}$ phase decreased significantly $(\mathrm{P}<0.05)$. These results indicated that BmK scorpion venom could induce $\mathrm{G}_{1}$ and $\mathrm{S}$ phase arrest in MCF-7 cells, thereby inhibit the growth of MCF-7 breast cancer cells. The results were shown in Fig. 4. 


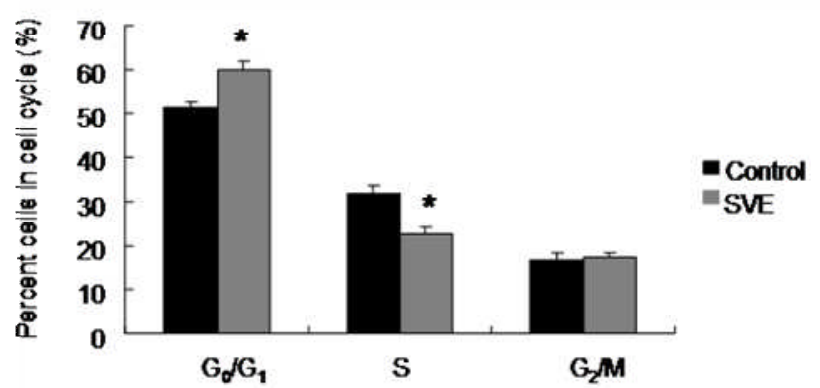

Figure 4: Effects of experimental BmK scorpion venom on the cell cycle of MCF-7 cells. Percentage of cells in different cell cycle phases after incubated with $600 \mu \mathrm{g} / \mathrm{mL}$ BmK scorpion venom extracts (SVE) for $24 \mathrm{~h}$ in MCF-7 cells by flow cytometry. Data shown are mean levels (+ SEM) from three independent experiments. T test was applied for statistical analysis. *, $\mathrm{P}<0.05$.

Effects of the BmK scorpion venom on the expression of cell cycle related protein Cyclin D1

Compared with the control cells without BmK scorpion venom, the expression of cell cycle-related protein CyclinD1 decreased in MCF-7 cells treated with $600 \mu \mathrm{g} / \mathrm{mL}$ of BmKs corpion venom after $24 \mathrm{~h}$. The results were shown in Fig. 5

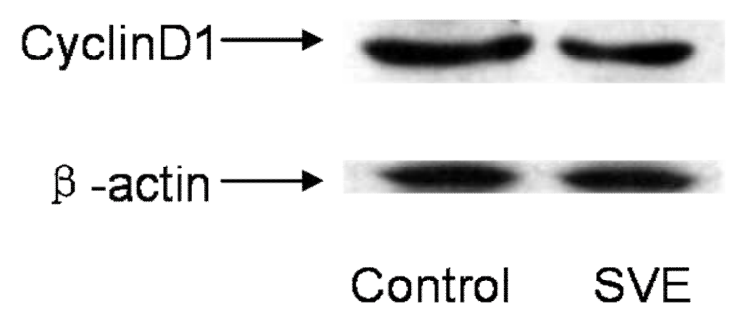

Figure 5: Effects of the BmK scorpion venom on the expression of cell cycle related protein Cyclin D1. Effects of scorpion venom on Cyclin D1 protein. MCF-7 cells were treated with $600 \mu \mathrm{g} / \mathrm{mL}$ of BmK scorpion venom extracts (SVE) for $24 \mathrm{~h}$. Protein from the total cell lysate was subjected to Western blot analysis for cyclin D1 protein. $\beta$-actin was used as an internal control. Representative results are shown from three independent experiments.

\section{Discussion}

Scorpion venoms have been used in Chinese folk medicine to cure cancer patients. The scorpion venoms extracts were mixtures of different toxins and peptides which showed different functions (Tiago EH, 2011). Our study demonstrated the anti-tumor effects of scorpion venoms extracts on breast cancer cells and liver cancer cells.

It has been shown that cell proliferation and apoptosis is to adjust a balanced state. Once the balance is broken by external factors, it will be followed with excessive cell proliferation or a large number of cells undergoing apoptosis. There are mainly two apoptotic pathways: activation of caspase- 8 initiates protease cascade to induce apoptosis; the release of cytochrome C-mediated activation of Caspase-3 to induce apoptosis (Zhang $\mathrm{X}, 2002)$. Bcl-2 is another protein related to apoptosis through regulating mitochondrial PTP opening and closing. Bcl-2 and Bcl-xL can inhibit PTP opening thereby inhibit the release of apoptotic factors and prevent the occurrence of apoptosis (Tsujimoto Y et al., 1985). Our work indicated that scorpion venoms inhibited proliferation of breast cancer and liver cancer cells in a dose and time dependent manner. More important, our results showed that the expression of pro-apoptotic protein caspase-3 increased while that of apoptosis suppression protein Bcl-2 decreased after the MCF-7 cells treated with scorpion venom. It could be preliminarily considered that the inhibition to the proliferation of MCF-7 cells by experimental BmK scorpion venom could be achieved by inducing apoptosis. 

http://dx.doi.org/10.4314/ajtcam.v11i5.17

Proliferation cycle of tumor cells: Tumor tissues are mainly composed of three cell populations, which are the proliferative cells, quiescent cells and those without the ability to proliferate. The tumor cells are characterized by unconstrained and indefinite proliferation (Laconi et al., 2001). All of the mechanisms that inhibit tumor cell proliferation or induce cell differentiation or apoptosis through affecting or regulating the cell cycle. The results indicated that the scorpion venom can significantly affected $\mathrm{G}_{1}$ and $\mathrm{S}$ phases, interfere with the regulation of the cell cycle and thus play the role of anti-tumor activity.

In tumor cells, proteins promoting cell cycle such as cyclin are usually over-expressed, while those inhibit cell division such as CKIs are often inactivated. Cyclin D1 has been paid more attention among various cell cycle regulators involved in malignancy evolution. Activation of cyclin D1 protein can inactivate pRb phosphorylation, which in turn inhibits the expression of cyclin D1, forming a negative feedback loop in late $\mathrm{G}_{1}$ phase ( Michalides et al., 1997). Therefore we suspected that the changes of cell cycle related to cyclin D1 expression observed. Our results demonstrated that expression of cyclin D1 in scorpion venom treated MCF-7 cells was indeed lower than that in the control cells cultured at the same period without drugs. In other words, the BmK scorpion venom could inhibit the growth of MCF-7 by affecting cell cycle. It was also reported that the inhibitory effect of BmK scorpion venom components to some tumor cells may be caused by affecting $\mathrm{G}_{1}$ phase with decreased expression of the cell cycle-related protein Cyclin E (Zhang et al., 2009). Therefore, there could be multiple mechanisms for the anticancer effects of BmK scorpion venom and that process might be complicated.

In conclusion, the BmK scorpion venom can inhibit the growth and proliferation of MCF-7 cells. The mechanism may be related to induction of apoptosis and blockage of the cells from $\mathrm{G}_{0} / \mathrm{G}_{1}$ phase to $\mathrm{S}$ phase. As a biological toxin, BmK scorpion venom is worthy of further in-depth exploration of its abundant physiological effects and broad application space.

\section{Acknowledgements}

The authors are grateful to the financial support from the National Natural Science Foundation of China (No. 81201563; No. 31371254).

\section{References}

1. Zhou X (1984), Progress in Biochemistry and Biophysics; 1: 20-25.

2. Wang Y, Lv X (2000), Advances in Purification of Scorpion Venom from Buthus Martensii and Pharmacological Effects, Chinese herbal medicine; 31:59-61.

3. Wu B, Gao C, Zhang Y, Zhou D (1993), In vitro inhibition and killing effects of scorpion venom biological extracts from Buthus Martensii on colorectal carcinoma. Journal of Chinese Anorectal; 4:3-6.

4. Fracchiolla, NS., Pruneri, G., Pignataro, L., et al. (1997), Molecular and immunohistochemical analysis of the bcl-1/ cyclin D1 gene in laryngeal squamous cell carcinomas: correlation of protein expression with lymph node metastasis and advanced clinical stage. Cancer; 79:1114-1121.

5. Btieler H (2010). Mitochondrial dynamics, cell death and the pat hogene-sis of Parkinson's disease. Apeptosis, 15(11): 1336-1353.

6. Hirsch T, Susin SA, Marz I, Marchetti P, Zamzami N, Kroemer G (1998). Mitochondrial permeaaliity transition in apoptosis and necrosis. Cell Biol Toxicol; $14(2): 141-5$.

7. Zargan J, Umar S, Sajad M, Naime M, Ali S, Khan HA (2011), Scorpion venom (Odontobuthus doriae) induces apoptosis by depolarization of mitochondria and reduces S-phase population in human breast cancer cells (MCF-7). Toxicol In Vitro; 25(8):1748-56.

8. Arber N, Doki Y, Han EK, et al. (1997), Antisense to cyclin D1 inhibits the growth and tumorigenicity of human colon cancer cells. Cancer Res; 57:1569-1574.

9. Tiago EH (2011), Ana Beatriz Gorini da Veiga: Arthropod venoms and cancer. Toxicon 57(4):497-511.

10. Zhang X (2002), Caspase-3 and apoptosis. Medical Review 2002; 8:621-623.

11. Tsujimoto Y, Cossman J, Jaffe E, Croce CM (1985), Involvement of the bcl-2 gene in human follicular lymphoma. Science; 228 (4706): 1440-3.

12. Laconi S, Pani P, Pillai S, et al. (2001), A growth-constrained environment drives tumor progression in vivo, Proc Natl Acad Sci USA; 98(14): 7806-11.

13. Michalides R, van Veelen N, Kristel PM, et al. (1997), Overexpression of cyclin D1 indicates a poor prognosis in squamous cell carcinoma of the head and neck. Arch Otolaryngol Head Neck Surg; 123:497-502.

14. Zhang YY, Wu LC, Wang ZP, et al. (2002), Anti-proliferation Effect of Polypeptide Extracted from Scorpion Venom on Human Prostate Cancer Cells in vitro. J Clin Med Res; 1:24-31.. 